\title{
EL CONCEPTO DE INDEPENDENCIA VASCA EN SABINO ARANA GOIRI ${ }^{1}$
}

\section{THE CONCEPT OF BASQUE INDEPENDENCE IN SABINO ARANA GOIRI'S WORKS}

\author{
Pedro José Chacón Delgado \\ UPV/EHU
}

Entregado el 19-6-2013 y aceptado el 22-1-2014.

\begin{abstract}
Resumen: Puede parecer una obviedad definir al nacionalismo por su independentismo, y quizás por eso la mayoría de los investigadores del nacionalismo vasco han recurrido al lema del primer partido nacionalista, JEL (Jaungoikua eta Lagizarra, Dios y Ley Vieja en euskera), para definir esta ideología, pensando que el concepto de independencia ya iba incluido, como así es, en el segundo término de dicho lema. Esta preeminencia por el lema ha conducido a la investigación a centrarse en si Sabino Arana Goiri le daba más importancia a la religión o a la raza, por ejemplo.

Pero priorizando el concepto de independencia, como hacemos aquí, para explicar el nacionalismo vasco, por encima del lema JEL, se obtienen resultados inesperados. Por ejemplo, que el concepto de independencia, por sí solo, es previo al lema JEL, puesto que a Luis Arana Goiri, hermano del fundador y quien se supone que le transmitió la «idea» al propio Sabino, le bastó con ser independentista para ser el primer nacionalista. El concepto de independencia vasca se utilizaba, en efecto, antes de que apareciera el nacionalismo pero se trata de saber si esta ideología le dio el mismo significado que tenía o si se lo modificó y cómo.
\end{abstract}

1 «Este trabajo se inscribe en el Grupo Consolidado de Investigación en Historia intelectual de la política moderna (IT-615-13), dirigido por Javier Fernández Sebastián y financiado por el Departamento de Educación, Universidades e Investigación del Gobierno Vasco - Eusko Jaurlaritza». 
Palabras clave: nacionalismo, tradicionalismo, carlismo, integrismo, raza

\begin{abstract}
It might seem obvious to define nationalism in terms of independence, and it is perhaps for this reason that most researchers into Basque nationalism have resorted to the slogan of the first nationalist party, JEL (Jaungoikua eta Lagizarra, God and Old Law in Basque), in order to define this ideology, thinking that the concept of independence was already included, as indeed it is, in the second element of this slogan. This focus upon the slogan has resulted in research being centred upon whether Sabino Arana Goiri attributed more importance to religion or race, for example.

But prioritizing the concept of independence, as I do here, to explain Basque nationalism, above and beyond the JEL slogan, produces unexpected results. For example, that the concept of independence itself predates the JEL slogan, given that for Luis Arana Goiri, the brother's founder and supposedly the person who transmitted the «idea» to Sabino himself, to be pro-independence was sufficient in order to be the first nationalist. The concept of Basque independence was used, in effect, prior to the apperance of nationalism, but the question is whether this ideology assigned it the same meaning that it already had, or if and how it modified this meaning.
\end{abstract}

Key words: nationalism, traditionalism, Carlism, fundamentalism, race. 


\section{EI lema JEL y el concepto de independencia}

Si aceptáramos la fecha de «hacia 1885» que se da en Historia del Nacionalismo Vasco en sus Documentos para los textos recogidos bajo el título de Pensamientos, tendríamos que aceptar que es entonces cuando por primera vez aparece el término «independencia» en Sabino Arana Goiri, cuando dice: «Los montes de Bizkaya son de hierro, que puede servir a quien ame su independencia» ${ }^{2}$. Pero tenemos al menos una prueba para afirmar la inconsistencia de esa fecha. Y es que en cierto momento de esos Pensamientos su autor nos dice «que se abre una cátedra euskérica (...) en Berlín, Viena o Filipópolis» ${ }^{3}$. A este respecto, cuesta creer que don Julio Urquijo no recogiera todas las ciudades europeas relacionadas con el euskera en su conferencia Estado actual de los estudios relativos a la lengua vasca pronunciada en el I Congreso Vasco en Oñate, de 1918. Y ahí, quien sin duda fue el mayor bibliófilo conocedor y recopilador de obras y datos sobre el euskera de su tiempo, no cita ni a Viena ni a Filipópolis, pero sí cita a Berlín, y en concreto a «la Baskische Gesellschaft (Sociedad Vasca) constituida en Febrero de 1886» y editora de la revista Euskara, Organ für die Interessen der «Baskischen Gesellschaft» que se publicó «desde el $1 .^{\circ}$ de Octubre de 1886 hasta el 1. ${ }^{\circ}$ de Julio de $1896 »^{4}$. Es casi seguro que Sabino Arana supo de la existencia de esta Sociedad Vasca de Berlín y de su revista Euskara por la revista Euskal-Erria de San Sebastián, que conocía muy bien, puesto que intentó publicar en ella sus primeros opúsculos ${ }^{5}$, y donde en su número 222 de 10 de septiembre de

${ }^{2}$ Historia del Nacionalismo Vasco en sus Documentos, Eguzki, Bilbao, 1991 (en adelante HNVD), tomo I, p. 118. En la p. 120 de estos Pensamientos, vuelve a salir el término «independencia», pero esta vez solo refiriéndose a la «Ley», segunda parte del lema. Dice así: «Ley, esto es, la ley tradicional, pura, sin sujeción a Estado alguno, absolutamente independiente, solo dependiente de las leyes divina y natural y de las buenas costumbres y usos del pueblo como determinantes inmediatos de la ley positiva».

3 Op.cit., p. 120.

4 Julio Urquijo, Estado actual de los estudios relativos a la lengua vasca, Imprenta Elexpuru, Bilbao, 1918, p. 25 y nota 2.

5 Todos rechazados (Etimologías euskéricas, Pliegos euskeráfilos y Pliegos históricopolíticos (I), ver O.C., vol. I, pp. 31, 43 y 70) hasta que consiguió que le publicaran «El proyecto de Academia Bascongada del Sr. De Artiñano» en octubre de 1886, de contenido indudablemente tradicionalista pero no nacionalista, como correspondía al ecléctico espíritu de la revista Euskal-Erria, cuya línea editorial era mayoritariamente liberal conservadora dinástica o alfonsina, pero que también albergaba mucho contenido tradicionalista cultural, sin hacer, no obstante, nunca propaganda de la dinastía carlista. 
1886, concretamente en su artículo titulado «El bascuence en Alemania», firmado por Manuel Gorostidi, se da cuenta de la fundación de la sociedad berlinesa y donde se recogen también, a continuación, los estatutos de dicha «Asociación Basca de Berlín» ${ }^{6}$. Por lo que al menos hasta septiembre de 1886 Sabino Arana no pudo tener conocimiento de esa relación de la capital alemana con la lengua vasca, lo cual retrasa sensiblemente la fecha de esos Pensamientos, al menos hasta finales de 1886.

De ello se deduce que la primera vez que el fundador del nacionalismo vasco utiliza y analiza el concepto político de «independencia» no es en Pensamientos, sino en los Pliegos Histórico-Políticos (I), escritos el 21 de abril de 1886 y publicados en Barcelona el 7 de abril de 1888 ante la imposibilidad de hacerlo antes, debido al rechazo del original por distintos periódicos, como él mismo relata en la «Advertencia» que encabeza este folleto. En una nota al pie dice que «autonomía» significa «gobierno independiente», pero que «casi nunca se usa dicha palabra en un sentido tan completo, pues el que más generalmente se le da es el relativo». Para él, por tanto, autonomía no tiene nada que ver con independencia absoluta y le interesa mucho recalcar la diferencia, puesto que ahí radica el error, a su juicio, de todos los que utilizan ese término: «si no lo hubiera creído, no habría hablado palabra». Por tanto, la única motivación que ha impulsado a Sabino Arana a intervenir en la polémica que origina este Pliego es el sentido «relativo» del concepto de «autonomía» vasca que se dirimía ahí y ante el que él opondría el de «independencia absoluta». Esta distinción la continuará haciendo durante todos sus escritos de aquí en adelante.

Para mayor abundamiento del concepto de «independencia relativa o limitada» que, según Arana, se utiliza hasta entonces a la hora de referirse a Bizkaya, continúa la misma nota: «Es también la acepción que se le ha atribuido por todos los escritores y periodistas euskerianos desde la última guerra civil, pues todos son políticos ultraibéricos, ya eclécticos, ya especialistas, y, siendo políticos españoles, no pueden menos de ser o nivelistas o autonomistas por regiones; es la misma acepción, en fin, que tiene en las páginas de los periódicos euskerianos que, considerando a Bizkaya como una de tantas regiones de España, la equiparan en derechos con todas ellas y muy especialmente con Cataluña; estúpida y ridícula monomanía de todo el que no sabe un átomo de historia en este asunto» ${ }^{7}$.

\footnotetext{
${ }^{6}$ En revista Euskal-Erria de San Sebastián, 222, 1886, pp. 193-198.

${ }^{7}$ La nota en cuestión es la número 1 de la página 74 del tomo I de las Obras Completas de Sabino Arana Goiri, Sendoa, San Sebastián, 1980. En adelante citaremos esta obra
} 
Estamos, por tanto, ante una prueba consistente para demostrar la novedad del pensamiento de Sabino Arana Goiri respecto de todo el fuerismo anterior. Y de ello deducimos que cabe perfectamente explicar el origen del nacionalismo vasco sin necesidad alguna de buscar «pre»o «proto» nacionalismo en ese último cuarto del siglo XIX, desde la ley abolitoria de fueros de 1876, ya que el propio fundador no reconocía antecedente alguno para su ideología. Y si él mismo no lo reconocía, ¿en base a qué se puede argumentar lo contrario? Sin duda, podemos apelar a una historia estructuralista, que quiera explicar el comportamiento de los individuos sin recurrir apenas a lo que ellos mismos decían de sí mismos: de hecho esa ha sido la línea dominante hasta ahora en el estudio del origen del nacionalismo vasco. Pero se podrá reconocer, al menos, que si los escritos mismos del fundador del nacionalismo explican las cosas de un modo determinado, habrá que concederles cierta relevancia en esa explicación de lo sucedido, por supuesto alguna más de la que se les ha dado hasta ahora. Lo que ocurría, según él, como vemos en esta última cita y en otras que aparecerán en este trabajo, es que siendo como había sido Bizkaya (respetando la grafía sabiniana) y los demás territorios vascos independientes absolutamente desde el principio de los tiempos, no había habido, al menos «desde la última guerra civil», ningún político, escritor o historiador que así lo hubiera postulado o defendido.

En la misma página donde aparece la nota antes comentada, hay otra, la número 2, donde cita la obra de Arístides de Artiñano El Señorío de $B i z k a y a^{8}$ y de la que se sirve para explicar la institución del Señor de Vizcaya, que habría coincidido desde 1379 con la de Rey de Castilla en la misma persona, pero que no habría implicado unión de ambas entidades territoriales ni dependencia de una respecto de la otra, según él, sino, antes bien al contrario, un concepto de autonomía entre ambas «idéntico al de independencia absoluta ${ }^{9}$. Y es así como para Sabino Arana se corrobora una realidad histórica en la que nadie hasta entonces había reparado, o que todos se empeñaban en ocultar, y que era, nada menos, la de la independencia absoluta de Bizkaya en toda su historia: «Bizkaya ha sido los pasados siglos legítimamente independiente, por serlo innata y

\footnotetext{
por sus abreviaturas O.C. Las cursivas, mientras no se diga otra cosa, son siempre de Sabino Arana.

${ }^{8}$ Sabino Arana cita la obra de Artiñano así, poniendo Bizkaya, cuando en el original es Bizcaya.

9 O.C., tomo I, p. 74.
} 
originariamente» ${ }^{10}$. Los términos «independencia»y «absoluta» aparecen unidos en tres ocasiones en estos Pliegos Histórico-Políticos (I).

Lo esencial en este asunto es que hasta los Pliegos de abril de 1886, donde Sabino Arana Goiri habla por extenso del concepto de independencia absoluta de Bizkaya, todavía no ha aparecido el lema Jaungoikua eta Lagizarra (JEL) ${ }^{11}$, ni siquiera en castellano. Es en Pensamientos precisamente, que hemos fechado como pronto para finales de 1886, donde aparecerá por primera vez la primera explicación del lema por antonomasia del nacionalismo vasco, resumen perfecto para su autor, Sabino Arana Goiri, de su ideología. Ahí se dice, siempre refiriéndose a los términos en castellano del lema, que «el segundo elemento de nuestro lema, Ley, debe subordinarse al primero, Dios» ${ }^{12}$, y englobando el término Ley a la Raza y a la Lengua.

\section{La «revelación» de 1882 y el concepto de independencia}

La conocida como «revelación» de $1882^{13}$, por la que supuestamente su hermano Luis le transmitiría la doctrina nacionalista, no aparece en la obra escrita de Sabino Arana Goiri hasta los conocidos como Apuntes íntimos, fechados, para los párrafos que aquí interesan, en mayo de $1887^{14}$. Será entonces cuando aparecerá también el lema JEL, todavía en castellano, pero más explícito todavía que en Pensamientos y utilizando unas expresiones casi idénticas a las que luego aparecerán en El discurso de Larrazabal. El lema en euskera, el que ha quedado hasta hoy, vendrá más tarde, por primera vez en la «Advertencia» de sus Etimologías euskéricas, de diciembre de $1887^{15}$.

10 O.C., tomo I, p. 75.

11 Al respecto resulta de obligada lectura el artículo titulado «Lema JEL», firmado por José Luis de la Granja, en Santiago de Pablo, José Luis de la Granja, Ludger Mees y Jesús Casquete (coords.), Diccionario ilustrado de símbolos del nacionalismo vasco, Tecnos, Madrid, 2012, pp. 593-608.

12 En HNVD, tomo I, p. 120.

$13 \mathrm{Al}$ respecto es imprescindible consultar el artículo de José Luis de la Granja «El culto a Sabino Arana: la doble resurrección y el origen histórico del Aberri Eguna en la II República», Historia y Política, 15, 2006, pp. 65-116.

${ }_{14}$ Fecha que nos da el editor de HNVD en tomo I, p. 108.

15 Ahí aparece por primera vez por sus iniciales en euskera: «J.-G. eta L.-Z.» (JaunGoikua eta Lagi-Zarra), en O.C., tomo I, p. 31. Ver al respecto también mi trabajo «Intro- 
Recapitulando la cuestión que aquí se dilucida: para cuando se despliega el lema JEL, aunque solo sea con sus términos en castellano (recordemos que Pensamientos es al menos de finales de 1886), Sabino Arana en sus Pliegos histórico-políticos (I) (que son de abril de 1886) ya nos ha hablado por extenso de la independencia absoluta de los territorios vascos respecto de España. Y lo más trascendental para el caso es que la supuesta transmisión de la ideología nacionalista, procedente de su hermano Luis, solo le ha llegado por mediación del concepto de independencia, no del lema JEL.

En efecto, en los Apuntes íntimos, Sabino Arana explica cómo, con unos «cortos conocimientos de la Historia de Bizkaya y en parte por ciertas dosis de reflexión», él ya sabía que «Bizkaya había sido siempre absolutamente independiente de España». Y que fue «el último año de esta etapa de mis evoluciones políticas», o sea 1882, tras «una larga discusión con mi hermano Luis, que ya para entonces era independiente absolutista, o sea nacionalista», que llegó al descubrimiento del lema Dios y Ley Vieja ${ }^{16}$. En El discurso de Larrazabal, del 3 de junio de 1893, cuando vuelve a contar, casi en los mismos términos que en Apuntes íntimos, el caso de la «revelación», dice que para entonces Luis era ya «bizkaino nacionalista» ${ }^{17}$. Pero, en cualquiera de los dos casos, Luis era nacionalista no porque conociera el lema JEL, algo para lo que Sabino necesitó una previa preparación y reflexión, según sus palabras, que solo empezaría a manifestarse por escrito, como hemos visto, a finales de 1886 como pronto, sino porque era «independiente absolutista», o sea «bizkaino nacionalista».

Con esta son ya, por tanto, muchas las razones para suponer que dicha «revelación» en el jardín de la casa familiar de Abando en 1882 jamás existió. Sin que el orden aquí implique rango de importancia: primera razón, porque el propio Luis ${ }^{18}$ nunca quiso o supo dar la más mínima explicación al respecto, cuando lo normal es que hubiera aclarado un asunto de seme-

ducción al estudio de la etapa barcelonesa de Sabino Arana Goiri (1883-1888)», Letras de Deusto, 134, 2012, pp. 155-182.

16 HNVD, tomo I, p. 108.

17 El discurso de Larrazabal, en O.C., tomo I, pp. 154-160. El relato de la «revelación» en pp. 157-158.

${ }^{18}$ La más completa biografía publicada hasta ahora es la reciente de Jean-Claude Larronde: Luis Arana Goiri (1862-1951) - Historia del nacionalismo vasco, Fundación Sabino Arana, Bilbao, 2010, donde tampoco se aporta nada nuevo al respecto. 
jante calado, y eso que tuvo oportunidad e incitación para hacerlo al elegirse la fecha de 1882, cincuenta años después, en 1932, como motivo para el primer Aberri Eguna de la historia del nacionalismo vasco. Segunda razón, porque el propio Luis dejó escrito un artículo en la revista Euzkerea, de 1934, titulado «Dos aciertos de Sabino», donde atribuye a su hermano las dos principales decisiones tácticas del primer nacionalismo, imbuidas de integrismo radical (no colaborar con ningún otro partido que no fuera católico y antiliberal a la vez, o sea con ninguno de los de entonces, y depurar al máximo el catolicismo de los militantes nacionalistas) ${ }^{19}$, aún a pesar de que Luis no lo tenía claro en un principio, lo que explica de modo bastante evidente que todo era obra de Sabino y que Luis se limitaba a seguirle, lo que no era poco, todo hay que decirlo, ya que hasta que Luis no volvió de Barcelona en abril de 1893 Sabino no se dispuso a iniciar su proselitismo político. Tercera razón, que no hay que despreciar tampoco de cara a la investigación, precisamente porque hasta ahora nunca se había puesto en cuestión: la posibilidad de que Sabino Arana no fuera siempre con la verdad por delante en sus textos. Hasta ahora el relato de la «revelación» de 1882 se ha dado siempre por cierto. Pero, ¿y si no lo fuera? ¿Por qué no podemos considerar esa posibilidad también con cierto detenimiento? ¿Que Sabino Arana no era capaz de mentir? Por supuesto que lo era y la prueba de ello la tenemos en Bizkaitarra, donde los artículos «Un Núñez», del número 18, y la serie que podemos denominar «de los maestros ficticios» que aparecen en los números 21, 22, 23 y 28, no solo están firmados con seudónimos de ocasión o directamente van sin firma, sino que se hacen proceder de lectores de Bizkaitarra, cuando es el propio Sabino Arana el que los escribe y finge recibirlos como director de la publicación, para apoyar sus propias tesis $^{20}$. Cuarta razón, por el testimonio de su coetáneo Juan de Olazábal y Ramery, en su periódico La Concordia, de 30 de marzo de 1932, con motivo de la celebración del primer Aberri Eguna de la historia, donde nos da un testimonio impagable sobre la evolución del de Abando desde el integrismo al nacionalismo, que cuadra perfectamente con nuestra hipótesis sobre la importancia capital de la etapa barcelonesa en la «conversión» de Sabino

19 Remito sobre el particular a mi artículo «Introducción al estudio de la etapa barcelonesa de Sabino Arana Goiri...» ya citado, p. 158.

${ }^{20}$ Esta cuestión la explico con detalle en mi trabajo «El pensamiento político de Sabino Arana Goiri: sobre falsos seudónimos y atribuciones erróneas», Letras de Deusto, 129, 2010, pp. 81-82. 
Arana $^{21}$. Y quinta, y de momento última, razón, deducible desde la historia de los conceptos, y que tiene que ver con el motivo de este trabajo sobre el concepto de «independencia»: para cuando en los Apuntes íntimos nos habla por primera vez de la supuesta «revelación» de 1882, el propio Sabino Arana ya nos ha explicado por extenso lo que para él significa la independencia absoluta de Bizkaya, clave de todo su ideario político, sin hacer mención para nada de ese acontecimiento.

Lo que más sorprende es que su hermano Luis ya fuera entonces nacionalista porque era «independiente absolutista». Si la revelación de 1882 se hubiera efectivamente producido, entonces Luis se habría adelantado al menos cuatro años a la configuración del lema nacionalista JEL, que sabemos que aparece en la obra de Sabino Arana Goiri entre finales de 1886 y finales de 1887 . A Luis entonces no le habrían hecho falta ni Dios ni Leyes viejas para ser nacionalista. Con ser independentista tenía suficiente. Lo que pensamos que realmente sucedió es que Sabino Arana atribuyó desde los Apuntes íntimos al concepto de independencia vizcaína del tradicionalismo un significado que, como veremos, nunca tuvo («que Bizkaya había sido siempre absolutamente independiente de España»), y luego se lo endosó a su hermano. ¿Por qué?: porque necesitaba implicar a más gente en su proyecto y su hermano era en principio el más próximo y el más seguro; para darle al origen de su ideología cierto halo de misterio e indefinición; por un prurito de vértigo o de timidez que le impedía colocarse él como único origen de todo; y sobre todo por borrar los años en los que estuvo en Cataluña, tan decisivos para conformar su ideología, procedente del integrismo español.

${ }^{21}$ En el artículo de portada titulado «¿El cincuenta aniversario de la fundación del nacionalismo vasco?» leemos: «por los años de 1882, Sabino de Arana y toda su familia eran carlistas; y carlistas siguieron siendo, hasta la separación de Nocedal y los suyos el año 1888, en que formaron en el integrismo, e integrista era D. Sabino de Arana, hasta que, tal vez por algunas diferencias con el señor Acillona, a la sazón figura saliente del integrismo en Vizcaya, pues estos incidentes los vamos olvidando, y después de cursar varios años la carrera de arquitectura en Barcelona, comenzó su evolución, vistiendo de abarcas en su casa de Albia, donde albergó dos jabalíes, y se dedicó a tirar a la barra, y adiestrarse en los ejercicios genuinamente vascos. Allí lo visitamos, dada nuestra íntima amistad ya antigua, y comunidad de ideas políticas; y nos enseñaba el primer proyecto de sus tarjetas en vasco «Arana eta Goiri'tar Sabiñ̄, unas etiquetas vascas también para botellas de chacolí; nos habló de la batalla de Arrizurrieta [sic], el aspa de San Andrés, presentándonos algunos diseños de la bandera bizcaína, etc. Y aún tardaría un par de años, en lanzar al viento su proyecto de nacionalismo vasco». El encuentro cabe fecharlo, por tanto, entre 1890 y 1891, según consideremos el inicio del nacionalismo vasco en Bizkaya por su independencia o en El discurso de Larrazabal y seguido la aparición de Bizkaitarra. 
Nadie hasta entonces había dicho que los vascos habían sido independientes de España en toda su historia hasta el siglo XIX. Tenemos, eso sí, antecedentes que utilizan, desde el fuerismo en todas sus vertientes, fundamentalmente la tradicionalista y la liberal conservadora, pero también la republicana federal, el concepto de independencia de los vascos y queremos saber si ese término «independencia» se refiere en todos los casos a lo mismo.

\section{El concepto de independencia en Bizkaya por su independencia}

Antes de abordar los antecedentes de Sabino Arana respecto del concepto de independencia, nos ocuparemos del texto donde aparece este ya completamente definido: Bizkaya por su independencia, publicado como tal en 1892 pero cuyos cuatro relatos aparecieron previamente en la revista La Abeja de Bilbao en 1890. Dichos cuatro relatos son versiones modificadas de unos hechos entre históricos y legendarios recogidos por toda la literatura fuerista vasca de la segunda mitad del siglo XIX. En esta obra Sabino Arana confiere a la independencia de los vascos un origen remoto, la cual es tan antigua como su sangre y su idioma ${ }^{22}$ y quienes la defienden en la historia lo hacen de modo belicoso y feroz: «eran hombres de una raza vigorosa, que amaban la independencia más que la vida» ${ }^{23}$, «gente vigorosa y ágil y de innata destreza y fieros por su independencia» ${ }^{24}$.

Pero sobre todo son dos ideas clave las que hay que señalar aquí como enriquecedoras del concepto de independencia que maneja Sabino Arana Goiri. La primera es respecto de la figura del Señor de Vizcaya, a la que también, de manera novedosa respecto de toda la historiografía anterior, le confiere un rasgo extremadamente perjudicial para el país, como agente de la españolización del mismo y causa final de la pérdida de la independencia $\operatorname{secular}^{25}$. Esta idea que podemos denominar del «Señor españoli-

22 O.C., tomo I, p. 115.

23 O.C., tomo I, p. 111.

24 O.C., tomo I, p. 113.

25 Basten dos citas de las muchas aducibles para mostrar esta idea nuclear de la historia vizcaína para Sabino Arana: «Ávidos de gloria y de honores exóticos los Señores de Bizkaya, enlazáronse con mujeres españolas de noble estirpe, y tomando parte activa en la reconquista de España, si bien en particular algunas veces, la mayor parte a las órdenes de uno u otro rey de la vecina nación, llegaron a adquirir títulos de nobleza española y a aceptar gustosos el de súbditos castellanos, consiguiendo más tarde que el Señor de Bizkaya fuera de sangre puramente española y concluyendo por que este título y el de Rey de Cas- 
zador» se repetirá luego a lo largo de toda la obra sabiniana. La segunda clave ya está dicha pero requiere comentario historiográfico: el enemigo contra el que combate Bizkaya no es cualquiera de los reinos que conformaban el norte cristiano peninsular mientras transcurrían las batallas narradas en Bizkaya por su independencia, sino España misma, a la que el de Abando da presencia política antes incluso de la llegada de los Reyes Católicos, la cual solo se producirá en la última de las batallas ahí narradas, la de Munguía, y solo por lo que respecta a Isabel la Católica. La «conclusión» que Arana ofrece al final de sus relatos es la siguiente: «Bizkaya, Confederación de Repúblicas independientes, lucha contra España, que pretende conquistarla, y la vence en Arrigorriaga (888), permaneciendo libre.-Bizkaya, República Señorial independiente, siendo súbdito de Castilla-León su Señor, lucha contra España, que pretende conquistarla, y la vence en Gordexola y Otxandiano (1355), permaneciendo libre.-Bizkaya, República Señorial independiente, siendo su Señor a un tiempo Rey de Castilla-León, lucha contra España, que pretende conquistarla, y la vence en Munguía (1470), permaneciendo libre ${ }^{26}$. Sea cual sea la coyuntura histórica que consideremos, incluso cuando ya los títulos de Vizcaya y Castilla corresponden a un mismo cetro (a partir de 1379), siempre será España la enemiga de Bizkaya.

Con este panorama, incluso sin necesidad de adentrarnos en su obra posterior, tenemos ya prácticamente conformado el concepto de independencia en Sabino Arana, consustancial a la raza vasca desde su mismo origen perdido en la noche de los tiempos, contrapuesto a España y a la españolización de Vizcaya causada por la figura del Señor. El fundador del nacionalismo vasco no tiene dudas de que Vizcaya y, por extensión Euskeria entera, fue independiente absolutamente de España en toda su historia y que los momentos en que pudiera parecer que más se imbricaba con ésta no era sino por voluntad y deseo o conveniencia de los propios vascos o incluso por ingenuidad o ignorancia de los mismos, cosa que siempre se podría resolver mediante el conocimiento de la propia historia.

\footnotetext{
tilla recayeran en una misma persona; hecho al parecer indiferente, puesto que no hería directamente a la independencia de Bizkaya, pero única causa en realidad de todos nuestros males» (O.C., I, 116); y otra, «la mil veces maldecida unión de ambos poderes, Real de España y Señorial de Bizkaya, en una persona: efecto de la institución señorial, y causa, a su vez, más determinante de la esclavitud que hoy nos oprime» (O.C., I, 128)

${ }^{26}$ En O.C., tomo I, p. 138.
} 
En Bizkaya por su independencia aparece también una identificación de «independencia» con «libertad exterior», que se matizará luego en escritos posteriores. Primero define «libertad» de modo contrario a como lo hace el liberalismo: «la palabra libertad, que en este párrafo empleo, significa lo único que rigurosamente puede significar, y no el estado de cosas de ese malhadado sistema político fundamental que se llama liberalismo, el cual nos aparta de nuestro último fin, que es Dios, y en la práctica coarta nuestro libre albedrío para lo bueno y lo indiferente. Se pretende hallar la libertad fuera de la obediencia a Dios y siguiendo los preceptos de Satanás, y no hay mayor necedad». Para a continuación diferenciar libertad interna y libertad externa, haciendo a esta última sinónimo de «perfecta independencia»: «Un pueblo será tanto más libre en su vida interna cuanto más fielmente observare los mandamientos de la religión y la moral verdaderas, porque tanto más imitará al Ser infinitamente libre, que es Dios; y tanto será más esclavo cuanto más los quebrantare, porque se asemejará tanto más al ser total y eternamente sometido, al prototipo del esclavo, que es Satanás. Y respecto a su vida exterior, entonces podrá disfrutar de perfecta independencia, cuando fuere virtuoso, pues la virtud es fuerza. Sin Dios no hay libertad. Este principio, bizkainos, esculpido lo tenéis en vuestro lema Jaungoikua eta Lagizarra. No lo olvidéis»27.

Más adelante, los conceptos de libertad interna y libertad externa se denominarán, respectivamente, «libertades» en plural y «libertad» en singular, siendo esta última sinónimo de independencia absoluta: «Por libertades (plural) se entienden los derechos o franquicias de un pueblo respecto de su poder o gobierno: por ejemplo, los de Bizkaya respecto de su Señor. Por libertad (singular), en la esfera política exterior o internacional, se entiende lo mismo que por independencia absoluta de una nación o estado respecto de los demás. Bizkaya rigurosamente hablando, no ha perdido sus libertades sino su libertad. El historiador bizkaino que sólo habla de los derechos, franquicias, libertades, etc., que se llaman Fueros, se calla, pues, lo principal: la independencia nacional. Y el bizkaino que sólo se queja de la pérdida de esas libertades, es extranjerista: no quiere la independencia nacional ${ }^{28}$.

27 Todas estas citas del concepto de «libertad» y su relación con «independencia», en O.C., I, p. 123 , nota 1.

${ }^{28}$ La cita en Baserritarra, n. 4 de 23 de mayo de 1897, O.C., II, p. 1276, nota 1. Llama la atención que sea el propio Sabino Arana quien remarque la diferencia entre libertad y libertades, precisando entre paréntesis que una es en singular y otra en plural y car- 
La independencia multisecular de Euskeria respecto de España es la pieza nuclear del pensamiento político e historiográfico sabiniano, a partir de la cual él construye todas las demás consecuencias de su ideología nacionalista. Y frente a la historiografía anterior y coetánea, él constata que hasta entonces nadie había afirmado tal cosa, con lo cual queda todo dicho respecto de la falta de antecedentes del mensaje nacionalista originario. Estamos ante una verdadera revolución de la tradición vasca y de su historiografía: «Todos los historiadores nacionales (a ninguno exceptúo) comienzan sus obras consignando y demostrando la independencia absoluta de Bizkaya. Leedlos, y allá veréis a nuestra Patria como nación aparte, con raza, lengua, territorio, leyes, poder e historia muy diferentes y distintos de los de España. Pero seguid leyendo, y en todos ellos tropezaréis al fin, con una página desde la cual, de buenas a primeras, DE BUENAS A PRIMERAS, repito, y sin hecho ninguno en que se funden, comienzan a llamar a España inuestra Patria común, nuestra Madre Patria! Y dígame ahora el Sr. Labayru si eso es, no ya patriotismo, pero ni criterio historial; dígame si eso no es trascendental vicio, dígame si no es eso de peores efectos que el exagerado patriotismo que ha conservado las leyendas; dígame si no es ésa la causa de nuestra ruina; dígame si pecho bizkaino puede sentir indignación proporcionada a los males que ese error nos ha acarreado» ${ }^{29}$ :

Aquí aparece citado Labayru, que empezó por entonces la publicación de su magna obra Historia General del Señorío de Bizcaya, cuyo primer tomo Sabino Arana se encargó de fustigar en Bizkaitarra empezando por sus imágenes y grabados. Pero lo mismo nos podríamos haber referido a Fidel de Sagarmínaga, líder del liberalismo fuerista intransigente tras la última carlistada, contra quien Sabino Arana descargó acerbas invectivas en Baserritarra debido a que el autor de Memorias históricas de Vizcaya consideraba compatible hablar de independencia de Vizcaya y al mismo tiempo de pertenencia a España: «el Sr. Sagarmínaga manifiesta que o no conoce nuestra independencia e instituciones tradicionales, o reniega de la primera, y no quiere las segundas más que en cuanto puedan ser compatibles con la constitución de su querida patria España y ventajosas para

\footnotetext{
gando de sentido político la primera sobre la segunda. Recordemos que un principio axial de la historia de los conceptos, establecido en su momento por Koselleck, es el de los llamados «singulares colectivos»: libertad, historia, etc.

${ }^{29}$ En Bizkaitarra, n. ${ }^{\circ} 30$ de 7 de julio de 1895, O.C., I, p. 644. Las versales y cursivas son originales de Arana.
} 
la prosperidad y ventura de la misma. (...) El Sr. Sagarmínaga era o muy corto de inteligencia o radical enemigo de nuestra tradición patria» ${ }^{30}$.

\section{El concepto de independencia vasca en autores anteriores a Sabino Arana Goiri}

El tema de la independencia originaria de los territorios vascos aparece constantemente en la publicística española de ámbito tradicionalista, y en general en toda la vasca, durante el siglo XIX. La cuestión está en saber qué significado se le daba entonces y si era el mismo que le dio Sabino Arana al iniciar su proyecto político. Sabemos, porque el propio fundador de este movimiento así lo dejó escrito, que se encontraba completamente solo cuando inició su proselitismo ${ }^{31}$, lo cual quiere decir que, hubiera o no influencia previa, esta no se materializaba por ningún lado, o al menos quien debiera haberse sentido heredero de ella no la hacía explícita en absoluto. Y tenemos también las citas de los autores de quienes pudo haber extraído esa idea de la independencia originaria: Arístides de Artiñano fundamentalmente y también Zamácola en parte. Y ninguno más. No cita, por ejemplo, a Ramón Ortiz de Zárate (1817-1883), tan del gusto de un estudioso del nacionalismo vasco como José Extramiana, que tanto contribuyó a identificar al tradicionalismo vasco con una suerte de prenacionalismo ${ }^{32}$. O a Dorronsoro, de quien Javier Corcuera recoge un par de veces una cita significativa con el término independencia por el medio $^{33}$. O a la mayoría de los supuestos precursores que estudia Vi-

30 Ambas citas de Baserritarra, n. 6 de 6 de junio de 1897, O.C., II, p. 1301.

31 «Mas cuando habiendo llegado a conocer a mi Patria y caído en la cuenta de los males que la aquejaban, extendí mi vista en derredor buscando ansiosamente un brazo generoso que acudiera en su auxilio, un corazón patriota, por todas partes tropecé con la invasión española que talaba nuestros montes y que, en vez de ser rechazada, era loca y frenéticamente secundada por indignos hijos de Bizkaya, y no hallé en ninguna un partido, una sociedad, un libro, un periódico, una página, una sola página, bizkainos que me escucháis, verdaderamente bizkaina.» En El discurso de Larrazabal, 3-6-1893, O.C., I, p. 157.

32 Ver José Extramiana, «R. Ortiz de Zárate: precurseur du nationalisme basque», en Hommage a Henry Bonneville, Grenoble: Université des Langues et Lettres de Grenoble, 1982, pp. 101-125.

${ }^{33}$ La cita en cuestión es: «Si Castilla no cumple su compromiso, indisputable es nuestro derecho a declarar rota la unión y recuperar nuestra independencia, como lo hicieron nuestros abuelos respecto al reino de Navarra, del que formó parte Guipúzcoa antes que de Castilla»; y aparece en las páginas 114 y 124 de La patria de los vascos, Taurus, Madrid, 2001. 
cente Garmendia ${ }^{34}$, como el ya citado Dorronsoro, o Navarro Villoslada, Esparza, Vildósola, Vicente Manterola, Rezusta, Ochoa de Zabalegui o Múzquiz, y de los que se vale también este autor para entender al tradicionalismo vasco como precursor del nacionalismo.

Además de los autores navarros citados anteriormente, como Navarro Villoslada o Ochoa de Zabalegui, otros estudiados recientemente por Iñaki Iriarte vienen a corroborar que el concepto de independencia es el que da sustento teórico a la foralidad navarra, pero en un sentido completamente alejado de pretensiones secesionistas, más bien todo lo contrario: como forma de justificar el privilegio de la Navarra foral en el seno de España. Así, por ejemplo, el diputado navarro Armendáriz, en la Sesión del Congreso de los Diputados de 16 de enero de 1837, proclamaba que Navarra había sido siempre «una Monarquía tan independiente, que en nada se asemeja al resto de la Nación española». Otro autor, Sagasti, con motivo de la Ley llamada paccionada de 1841, por la que Navarra pasa de ser reino a provincia foral, recuerda «el pacto solemne de respetar sus leyes y su independencia, identificadas empero éstas con los principios de la Constitución general de la Monarquía». Hasta llegar a la obra de Serafín de Olave, de 1878 , cuyo título bien significativo es El pacto político como fundamento histórico general de la nacionalidad española y especialmente como manifestación legal de la soberanía independiente de Navarra en unas épocas y en otras de su autonomía sin perjuicio de la unidad nacional. Todos estos autores combinan de modo natural la independencia secular de Navarra y su pertenencia a España, tomando como referentes históricos tanto la conquista de 1512 como la conversión del viejo reino en provincia foral de $1841^{35}$.

A Juan Antonio de Zamácola lo cita Arana en el número 7 de Bizkaitarra (31-3-1894) en los siguientes términos, y la cita es interesante transcribirla entera: «Pero el carácter común de todos los partidos españolistas (por eso los llamamos así) es el de considerar a Bizkaya como parte integrante de la nación española. De ello son los causantes principales los escritores de nuestro país. El único que se acercó algún tanto a la verdad fue el arratiano D. J. A. de Zamacola en su obra titulada Historia de las $\mathrm{Na}$ -

34 Vicente Garmendia: Jaungoicoa eta Foruac. El carlismo vasconavarro frente a la democracia española (1868-1872), UPV-EHU, Servicio Editorial, Leioa, 1999.

35 En Iñaki Iriarte: «La provincia foral. La nostalgia de la independencia», en Carlos Forcadell y Mari Cruz Romeo (eds.), Provincia y nación. Los territorios del liberalismo, Institución «Fernando el Católico», Zaragoza, 2006, pp. 143-158. Las citas tomadas de pp. 150,154 y 156 respectivamente. 
ciones Bascas; pero tampoco llegó a exponerla con exactitud. Del estudio de nuestros autores nace el que después los escritores extranjeros incurran en el mismo vicio de juzgar históricamente a Bizkaya como región española, aunque de las más nobles y preciosas. Y de aquí el que, siendo la mayor parte los lectores que estudian más a los autores que las cosas por ellos tratadas, no se encuentre en la prensa de nuestra Patria una sola columna que reconozca a Bizkaya la naturaleza y condición que le son propias, ni se tropiece con un solo profesor de historia o de geografía que enseñe a sus discípulos lo que en realidad ha sido y es Bizkaya, y no lo que pretenden que sea quienes no han sabido estudiarla, o son sus implacables enemigos» ${ }^{36}$.

De nuevo se refuerza aquí nuestra teoría de que Sabino Arana Goiri no reconoce precursores, por lo que quienes hablan de «pre» o «proto» nacionalismo tienen que prescindir, para sostener sus teorías, de lo que dice el propio fundador del nacionalismo, cuestión bastante complicada de sostener, a mi juicio. De Zamácola en su Historia de las Naciones Bas$\operatorname{cas}^{37}$ Arana Goiri maneja conceptos, como sobre todo el que tiene que ver con la idea de independencia de las provincias vascas, entendida al modo republicano, que actuarían autónomamente en asamblea, rigiéndose a sí mismas en todo y confiando su protección a quien ellas estimaran oportuno en cada coyuntura histórica, pero siempre necesitando de dicha protección, dado su tamaño respecto de unidades políticas más poderosas. Pero el planteamiento global de este autor incluye también un españolismo tan evidente que a Sabino Arana le impedirá convertirlo en precursor.

Pero vayamos por partes. En el volumen II de Historia de las Naciones Bascas, empieza por su «época séptima» que titula «Unión de las provincias bascas de España a la Corona de Castilla», donde equipara los tres territorios vascos como independientes «en su constitución y fueros». Al referirse en particular a Vizcaya, hace a sus señores «en un todo independientes de la corona de Navarra, Leon, Castilla y demás con quienes tuvieron federado aquel estado en diferentes épocas, pues que cuando no se cumplía por los reyes sus protectores los tratos y conciertos que estipulaban, se desnaturaban de sus estados y se iban a la protección de otro monarca, llevándose

36 O.C., tomo I, p. 260.

37 Publicada originalmente en tres volúmenes en Francia, concretamente en Auch (capital histórica de la Gascuña, situada entre Pau y Toulouse), en 1818, y que es la edición que aquí vamos a seguir. 
consigo el estado de Bizcaya, y algunas veces los de Guipúzcoa y Alaba, entregando solamente a los reyes que dejaban lo que era suyo» ${ }^{38}$.

Este republicanismo vasco descrito por Zamácola hay que ponerlo en contraste con lo que hoy conocemos sobre aquellos regímenes políticos provinciales respecto de la Corona de España. Así, la idea de una república como organización provincial o supramunicipal que podía prescindir a voluntad de la figura del Señor, tesis de Sabino Arana, u optar con su Señor por el Monarca que mejor le conviniera en cada coyuntura histórica, tesis de Zamácola, no resiste el menor análisis ${ }^{39}$. Las provincias vascas tuvieron una conformación histórica mucho más accidentada que todo eso. Las luchas de banderizos hubieron de ser atajadas por la intervención de instancias superiores a los contendientes, y de poner coto a aquel desorden se encargaron primero el Señor consorte Juan Núñez de Lara y luego el Corregidor Gonzalo Moro, enviado por el rey Enrique III de Castilla, que era a la vez Señor de Vizcaya, desde que en 1379 su padre, Juan I, uniera en su cetro ambos títulos. Vizcaya, primer objeto de interés histórico de Sabino Arana, no vio su estructura provincial conformada tal como la conocemos hoy hasta el siglo XVII, puesto que entonces se incorpora Durango en 1628 a la llamada «Vizcaya nuclear», la que va del Nervión al Deba, y en la segunda mitad de ese siglo las Encartaciones, y solo con la «Carta de Unión» de 1630 se supera la división histórica entre Villas y Tierra Llana. Y todo ello sin que la memoria de las luchas de bandos se olvidara nunca en la organización del Señorío, de profundas que fueron las heridas que dejó, en contra de la imagen igualitaria y arcádica que siempre nos transmite Sabino Arana del pasado vizcaíno: la prueba está en que en la elección de junteros y diputados, y hasta la Ley de 1876, se seguían reservando los puestos equitativamente para miembros de cada uno de los dos bandos, el oñacino y el gamboíno ${ }^{40}$.

${ }^{38}$ Historia de las Naciones Bascas, op.cit., vol. II, las citas en las pp. 12, 25 y 92-93 respectivamente.

39 Véase, por ejemplo, al respecto, de José María Portillo Valdés y José María Ortiz de Orruño, «La foralidad y el poder provincial», Historia Contemporánea, 4, 1990, pp. 107-122. Y de María Rosa Ayerbe Iríbar, «Las Juntas Generales Vascas: en defensa de la foralidad y de los derechos históricos», Ius-Fugit: Revista interdisciplinar de estudios histórico-jurídicos, 15, 2007-2008, pp. 303-337, especialmente, por lo que aquí respecta, pp. 303-312.

40 Véase Adrián Celaya Ibarra, Los Fueros de Bizkaia, Academia Vasca del Derecho, Bilbao, 2009, sobre todo su primera parte «Cómo nacieron»; Coro Rubio Pobes, La identidad vasca en el siglo XIX, Biblioteca Nueva, Madrid, 2003, pp. 88-90; Joseba Agirreazkuenaga (dir.), Diccionario biográfico de los diputados generales, burócratas y patricios de 
Con Zamácola estamos ante un escribano, gran experto también en folklore español, concretamente en copla y en baile, que sirvió para la administración de José I en Madrid y que luego tuvo que marchar de España ante el peligro de represalias por la vuelta del nuevo régimen de Fernando VII, a partir de $1814^{41}$. Y es por ello que en este libro se encarga de disipar ese peligro alabando la vuelta de Fernando VII al trono en 1814, tras la derrota de los franceses, así como su decreto anulatorio de la labor de las Cortes de Cádiz, que se reproduce también en el tomo II de su Historia y, con ello, la recuperación de los fueros de Bizcaya, conculcados por la Constitución de $1812^{42}$.

En el tomo III de la primera edición de Historia de las Naciones Bascas que seguimos aquí, nos encontramos con un tópico que luego se repetirá con Sabino Arana a la hora de comparar a los nativos vascos con el resto de españoles que llegaban al calor de la primera industrialización: «Los habitantes de Bizcaya son robustos, fuertes, ágiles, activos, honrados y trabajadores, tanto que se puede decir sin exageración, que un jornalero de Bizcaya trabaja más en un día, que tres habitantes de las provincias interiores de España». Pero luego, cuando hace otros comentarios sobre el resto de cualidades de los vascos, aun favorecedores para ellos respecto del resto de españoles, hay una cuestión que seguro no le convenció demasiado al fundador del nacionalismo vasco, y es que Zamácola consideraba a vizcaínos y navarros como unos españoles más, sin que las diferencias afectaran a la unidad entre todos ellos. Así, refiriéndose a los vizcaínos, nos dice: «cualquier otro Español se precia de tener un amigo Bizcayno con quien desahogar su pecho, sin miedo de que publique jamás sus debilidades». Y lo mismo con los navarros, les reconoce sus virtudes pero habla de ellos como otra clase más de españoles: «El genio de los Navarros es pundonoroso, liberal y franco: aman su país y sus costumbres, y hoy son de todos los Españoles los que cuidan más de la limpieza y aseo de sus personas» ${ }^{43}$.

Bizkaia (1800-1876), Bizkaiko Batzar Nagusia-Juntas Generales de Bizkaia, Bilbao, 1995, pp. 20-26; y Javier Ybarra y Bergé, Política nacional en Vizcaya, Instituto de Estudios Políticos, Madrid, 1947, pp. 57-59.

${ }^{41}$ Ver Javier Fernández Sebastián, La génesis del fuerismo, Siglo XXI, Madrid, 1991, pp. 258 y ss., en el que reclama un estudio en profundidad sobre este autor, del que destaca a un tiempo, por un lado una vertiente folklorista muy acusada, como defensor de la música y el baile españoles frente a las modas foráneas («chauvinista [español se entiende] musical» lo define Fernández Sebastián), y al mismo tiempo afrancesado.

${ }^{42}$ Historia de las Naciones Bascas, op.cit, vol. II, ambas cuestiones, decreto anulatorio de la Constitución y recuperación de los Fueros, en pp. 234-244 y 245-246 respectivamente.

${ }^{43}$ Op.cit., vol. III, citas en las pp. 47, 52 y 217 respectivamente. 


\section{El concepto de independencia vasca en autores coetáneos a Sabino Arana Goiri: Arístides de Artiñano y Zuricalday}

Entre quienes utilizan el concepto de independencia vasca antes de Sabino Arana y que pudieran efectivamente haberle influido hay que situar en un muy primer lugar al ya citado Arístides de Artiñano. Conocemos bastante de la vida y obra de este personaje gracias a un trabajo espléndido de Juan Gracia Cárcamo, caracterizado por su precisión y rigor a la hora de buscar concomitancias y relaciones con el fundador del nacionalismo vasco $^{44}$. De lo que no hay duda es que Artiñano y Arana coincidieron y se trataron en Barcelona, donde el autor de El Señorío de Bizcaya vivió entre 1876 y 1906. Y prueba de ello es el tema de la traída de los restos de Valentín de Berriotxoa por el puerto de Barcelona, en la que intervino muy directamente Artiñano y en la que estuvieron presentes los hermanos Arana, de lo que hablan luego sus primeros biógrafos ${ }^{45}$, así como el artículo de Arana «El proyecto de Academia Bascongada del Sr. De Artiñano», publicado en la revista Euskal-Erria en octubre de $1886^{46}$. Este trabajo, temprano y, por su contenido, insólito sin duda entre los del fundador del nacionalismo vasco, nada propenso a glosar a otros autores, salvo para adaptarlos a su ideología, denota un conocimiento directo de Artiñano por parte de Arana, pero no trasluce los rasgos ideológicos propios del nacionalismo vasco y se inscribe en lo que entonces era el tradicionalismo vasco españolista. Arana debió pensar, sin duda, que esa era la única forma de que le publicaran algo en la prestigiosa revista Euskal-Erria de San Sebastián.

Pero hay que volver veinte años atrás para encontrar la primera obra que nos interesa de Artiñano a estos efectos. Se trata de su Biografía del Sr. D. Pedro Novia de Salcedo, Padre de Provincia y primer benemérito del M.N. y M.L. Señorío de Vizcaya. Este libro cuenta con una introducción de José Miguel Arrieta-Mascarua, que por cierto aparece citado un

44 «Antes y después del nacionalismo. Arístides de Artiñano: una vida consagrada a través de su obra histórico-jurídico-política, a la «santa causa foral» (1840-1911)», Notitia Vasconiae, 1, 2002, pp. 361-409.

45 Javier Corcuera recoge el caso, citando a uno de esos primeros biógrafos de Arana, Basaldúa, en La patria de los vascos, Taurus, Madrid, 2001, p. 202.

46 En la «Advertencia de los editores» de sus Obras Completas, se dice que este artículo lo escribió Sabino Arana el 20 de julio de 1886. Luego se da erróneamente la localización de dicho artículo en la revista Euskal-Erria (O.C., III, pp. 2299-2303). Hemos comprobado que no apareció en el n. ${ }^{\circ} 217$, sino en el n. ${ }^{\circ} 227$, de 30 de octubre de 1886, pp. 361-364 del tomo XV de la reproducción facsímil de la revista en La Gran Enciclopedia Vasca. 
par de veces en las obras de Sabino Arana justamente para tomar distancia ideológica respecto de é ${ }^{47}$. En esta citada biografía de Novia de Salcedo aparece el término «independencia» en treinta ocasiones. De las cuales dieciséis corresponden a citas del propio Novia de Salcedo. En todas ellas no se habla de independencia de Vizcaya o de las Vascongadas respecto de España y sí en una ocasión respecto de Castilla, que es de lo que en definitiva se trata. Porque aquí deja muy claro Novia de Salcedo, tal como recoge en cita Artiñano, que lo que quiere es demostrar la independencia respecto de los demás estados que conforman la monarquía española: «cuando cada uno de los varios estados reunidos por las circunstancias bajo una sola cabeza, difiere en legislación y formas de regirse, conserva el indestructible carácter de la independencia de que gozó y goza, si no existen pruebas demostrativas de haberlas adquirido por mera gracia y donación del jefe común a que está subordinado. Con este sólido principio ha sido siempre y es bien fácil discernir los varios y distintos estados que unidos e incorporados vinieron a constituir la monarquía española». De lo que no hay duda en ninguna parte del texto es de la consideración en que se tiene a España, de la que se habla como nación y de la propia consideración que tiene de sí mismo el autor de este texto: «seamos lo que nunca debimos dejar de ser, Españoles y solamente Españoles ${ }^{48}$.

La siguiente obra de Artiñano, para lo que nos interesa, fue Jaungoicoa eta Foruac. La causa vascongada ante la revolución española, de 1869, donde aparece el término «independencia» para referirse al País Vasco en 19 ocasiones, pero solo en una de ellas se refiere a la instancia respecto de la que reivindica la independencia, y esa es la corona de Castilla, no España. Así, acudiendo a la autoridad de Pedro Novia de Salcedo, que es su única cita constante para documentarse en esta cuestión, concluye: «nada puede darse más decisivo para patentizar y marcar de un modo absoluto la independencia y separación de los Estados de Castilla y de Vizcaya ${ }^{49}$. El término «unidad», en cambio, es muy importante para conocer el pensamiento político de Artiñano en este folleto y entender también de qué habla cuando

47 «El Sr. Arrieta-Mascarúa, que por cierto estaba muy lejos de nuestras doctrinas políticas», Bizkaitarra 15 (30-09-1894), O.C., I, p. 377.

${ }^{48}$ La Biografía de Novia de Salcedo, impresa en Viuda de Delmas, Bilbao, 1866. Las citas son de sus páginas 142 y 86 respectivamente. Adaptamos la ortografía al modo actual.

49 Reproducido por Vicente de Garmedia en Jaungoicoa eta Foruac. El carlismo vasconavarro frente a la democracia española (1868-1872), UPV-EHU, Servicio Editorial, Leioa, 1999, p. 164. 
utiliza el término independencia. Así «unidad» aparece en este folleto en 26 ocasiones, de las cuales la forma mayoritaria es referida tanto a la unidad católica, en 9 ocasiones, como a la «unidad religiosa», en 6. En otras 5 ocasiones se refiere también al mismo tipo de unidad pero siempre referido a España. Hay una ocasión más en que habla de «unidad nacional» y 3 en las que se refiere, despectivamente a la «unidad constitucional». Las otras dos citas que quedan, «unidad social» y «unidades» en plural, aparecen dentro del siguiente párrafo que, a mi juicio, es el más significativo del concepto de unidad que maneja referido a España: «España, pues, por su origen, por su historia, por sus sentimientos, por su carácter y modo de ser, porque es España y no puede dejar de serlo ha sido, es y será eminente y profundamente católica y solo católica, firmemente penetrada de que en la unidad religiosa encuentra un lazo seguro que aúne las voluntades de sus pueblos, que les proteja en su independencia, que mantenga su unidad social, que coordine y dirija todas sus fuerzas para poder presentarse tan grande, tan hidalga tan valiente como tiene el deber de mostrarse siempre ${ }^{50}$. Estamos ante la consideración de la religión católica como vínculo interno de unidad política, típico del tradicionalismo español como veremos más adelante.

Posteriormente, en El Señorío de Bizcaya, histórico y foral, de 1885, Artiñano vuelve a utilizar el término independencia profusamente, pero sin variar el sentido de independencia absoluta de Vizcaya respecto de Castilla, no de España. Constatamos que la consideración que Artiñano tiene de la figura de los Señores de Vizcaya es totalmente contraria a la que luego expresará Arana. Así, en Artiñano, leemos: «Bizcaya creció y se desarrolló al amparo de sus Señores, que la prestaron toda su amorosa solicitud...»51. Y la Batalla de Munguía, que para Sabino Arana fue una de las cuatro por las que Vizcaya demostró su independencia originaria, en realidad vino dada por la opción del Señorío a favor de la futura Isabel la Católica, desposeyendo de tal condición a Enrique IV, quien por esta causa le hizo la guerra a los partidarios de Isabel en Vizcaya, lo que le sirve a Artiñano para deducir que: «Queda, pues, Enrique IV desposeído del Señorío de Bizcaya, que desde aquel acto solo reconoce la soberanía de D. ${ }^{a}$ Isabel. Reclamamos, pues, para nuestro País la gloria de que la primera corona que ciñó las sienes de la gran Reina Católica, fue la de la Señoría de Bizcaya [sic], lauro y honra que nadie puede negar a este

\footnotetext{
50 Op.cit., pp. 135-136.

51 Arístides de Artiñano y Zuricalday, El Señorío de Bizcaya histórico y foral, La Peninsular, Barcelona, 1885, p. 102.
} 
nobilísimo lugar.» Y continúa: «No necesitamos realzar la trascendencia de este hecho histórico, que prueba la absoluta independencia de Bizcaya. En plena Monarquía, cuando ya el Señorío se ha transmitido cuatro veces, desde su incorporación a Castilla, y ha pasado un siglo viviendo en esa unión, falta a sus juramentos un Monarca, y Bizcaya, recordando sus derechos, le niega la obediencia y elige otro Señor. ¿Qué es esto más que la confirmación plenísima de su soberanía e independencia? $\gg^{52}$.

Y si por fin recurrimos directamente a la fuente en la que se basa el propio Artiñano, esto es a Pedro Novia de Salcedo, en su Defensa Histórica, primera parte, capítulo XVIII «Concepto de separadas y distintas de Castilla de que han gozado las Provincias Bascongadas después de su unión a la corona», leemos: «La independencia de un estado no consiste en no tener superior, no consiste en esta ó aquella forma de regirse y gobernarse, sino en que este superior, en que esta ó aquella forma de gobierno, sea propia y privativa suya, y no dimanada del gobierno de otro estado» ${ }^{53}$. En definitiva, que es Vizcaya o las Vascongadas las que han elegido esa forma de estar en España, junto con las demás unidades políticas que conforman la monarquía, pero sin supeditarse a ellas y sin intermediario alguno respecto de la Corona que las une a todas. O dicho en palabras de Novia de Salcedo: «Con este sólido principio ha sido siempre y es bien fácil discernir los varios y distintos estados que unidos e incorporados vinieron a constituir la monarquía española» ${ }^{54}$. Estamos, así, ante lo que desde el tradicionalismo se conoce como vínculo externo de la unidad política de España: la Monarquía.

\section{La evolución de Sabino Arana Goiri desde el integrismo español al nacionalismo vasco a través del concepto de independencia}

En el primer documento oficialmente integrista ${ }^{55}$, de 1888 , la desvinculación respecto de la Monarquía carlista se pone de manifiesto, tras un

52 Op.cit., p. 109.

${ }_{53}$ El libro se titula Defensa Histórica, Legislativa y Económica del Señorío de Vizcaya y provincias de Álava y Guipúzcoa, publicado en Librería Delmas, Bilbao, 1851, y según Arístides de Artiñano en su Biografía de Novia de Salcedo ya citada (p. 136), escrito entre mediados de 1827 y diciembre de 1829. Citamos por la reproducción facsímil de Amigos del Libro Vasco, Echevarri, 1987, en cuatro volúmenes. La cita en la p. 397 del primer volumen.

${ }^{54}$ Defensa Histórica, op. cit., tomo I, p. 399.

55 El documento en cuestión es el titulado Manifestación hecha en Burgos por la prensa tradicionalista el mes de julio de 1888, Madrid, Imprenta de Gabriel López y del Horno, 1906. 
periodo de desavenencias iniciado en 1885, con la muerte de Cándido Nocedal, director de El Siglo Futuro y delegado del Pretendiente carlista en España, cuyos seguidores, empezando por su propio hijo, Ramón Nocedal, vieron cómo Don Carlos inició, a partir de entonces, un progresivo distanciamiento del círculo más estrecho en el que antes se apoyaba para llevar a cabo su política en España. En este documento se critica continuamente la inconsistencia ideológica del Pretendiente carlista y de sus seguidores con expresiones tales como: «con toda solemnidad se han presentado las tres palabras de nuestro lema Dios, Patria y Rey, barajadas y confundidas, sin orden de prioridad» ${ }^{56}$. Cabe recordar una vez más que Sabino Arana utilizó con profusión el lema Jaungoikua eta Lagizarra, muy similar al carlista Jaungoicoa eta Foruac, o al propio integrista de Dios y Patria (sin Rey), dándole mucha importancia al orden y al significado de sus términos. En lo que aquí nos ocupa, la cuestión clave para los integristas del manifiesto era mantener el orden de los términos del lema, tal como aparecen enunciados: la palabra clave es «barajadas». En el artículo «Fuerismos falsos» del número 7 de Bizkaitarra (31-3-1894) dice Sabino Arana, respecto de los que no son nacionalistas: «unos prescinden del elemento Jaungoikua, otros del Lagizarra, otros del eta, quién confunde en uno solo el Jaungoikua con el Lagizarra, quién los permuta de lugar y los baraja» ${ }^{57}$.

El fundador del nacionalismo vasco ya ha tenido ocasión de conocer en Barcelona, donde está entonces (1883-1888), la obra de Félix Sardá y Salvany (El liberalismo es pecado es de 1884 y El apostolado seglar, tan decisiva o más que la anterior, es de 1885). En la Manifestación hecha en Burgos por la prensa tradicionalista, ya citada, se dice que desde los primeros meses de 1887 se venía gestando la ruptura a propósito de una Orden del Pretendiente que implicaba una nueva organización para el tradicionalismo, y que aparece transcrita en El Siglo Futuro, periódico-referencia para toda España de la doctrina íntegra, en la primera página del número de 23 de marzo de 1887, bajo el titular «Documentos importantísimos» (y recordemos, al respecto, que los Apuntes íntimos de Sabino Arana, donde aparece la primera noticia de la «revelación» son de un par de meses después: mayo de 1887). Dicha Orden supone, a juicio de los íntegros, querer reforzar la figura del Rey en detrimento de los otros dos principios del lema que iban por delante, Dios y Patria, y significa el ger-

\footnotetext{
56 Op.cit., p. 6.

57 En O.C., tomo I, p. 260.
} 
men de lo que luego tomará cuerpo y supondrá la ruptura del carlismo y la aparición del integrismo.

El integrismo refuerza los poderes intermedios correspondientes a las diferentes circunscripciones políticas que conforman la monarquía, abomina de los partidos políticos y concede al rey la potestad de resolver pero con el visto bueno de las Cortes y por el bien de la comunidad: «En las Cortes los reinos mismos, las fuerzas vivas del país y los consejos, por sus mandatarios o mensajeros, que no los partidos ni sus diputados que ahora nos tiranizan y destrozan, miran por sus fueros que si no es a su gusto no les pueden quitar ni mudar... Así el rey, poder único, reina y gobierna, y él y solo él resuelve; pero no como quien maneja rebaños de su propiedad, sino como quien está puesto para regir a hombres libres y racionales, y en bien de la comunidad ${ }^{58}$. Este es el significado de la teoría del pactismo tradicionalista.

Hay que entender, por tanto, el integrismo como un movimiento católico extremado, en el que hay que situar desde el principio a Sabino Arana Goiri, animado en Barcelona por Félix Sardá y los jesuitas a los que frecuentaba a diario en la residencia de la Compañía en la calle Caspe, muy cerca de su domicilio en la ciudad condal. Sin este contexto histórico es imposible entender el tránsito de ser carlista per se a ser carlista per accidens, expresión que tanto le gustaba utilizar al de Abando para explicar la «revelación» de 1882 y el comienzo de su doctrina, que la usó tanto en Apuntes íntimos como en El discurso de Larrazabal, y que, a la postre, resulta ser una expresión típica del integrismo que aparece en los textos del momento, y por momento nos referimos aquí al año anterior a la ruptura de mediados de $1888^{59}$.

58 Manifestación hecha en Burgos por la prensa tradicionalista, op.cit., p. 26.

${ }^{59}$ En el segundo semestre de 1887 aparece una serie de artículos titulados «El integrismo y la política» en la revista Dogma y razón, reproducidos también en El Siglo Futuro, donde se empieza a gestar la desafección del integrismo respecto del carlismo. En un artículo de la serie, fechado el 10 octubre de 1887, aparece un párrafo donde se dice: «El Integrismo no es bandera de un partido per se; hay un partido per accidens que forma parte del Integrismo, porque no es partido, sino comunión de los hombres de buena voluntad que desean salvar la España por medio de un gobierno íntegramente católico» (citado por Solange Hibbs-Lissorgues, Iglesia, Prensa y Sociedad en España (1868-1904), Alicante, Diputación, 1995, pp. 122 y 307). La utilización de los términos «per se»y «per accidens» es típica del escolasticismo tomista. Sabemos que Sabino Arana estaba suscrito a El Siglo Futuro (lo dice en la «Carta al P. José Ignacio de Arana, S.J.», de 19 de julio (garila) 1893, en HNVD, tomo IV, 660). Desde luego la prueba es evidente de que solo por medio del integrismo podía un tradicionalista dejar de ser car- 
El tradicionalismo español, del que forma parte el integrismo, y del que parte también, obviamente, el nacionalismo vasco, reconoce que sin unidad religiosa no es posible, ni concebible siquiera, la unidad política ${ }^{60}$. El tradicionalismo, así mismo, reconoce la singularidad propia de las diferentes partes territoriales constitutivas del Estado, respecto de las cuales la religión ejercería de vínculo interno, mientras que la Corona sería el vínculo externo $^{61}$. Por otra parte, ni siquiera es necesario recurrir a los tradicionalistas vascos para encontrar el concepto de independencia de las unidades que conforman la Monarquía española: lo descubrimos también en autores típicos del tradicionalismo no vascos, como el propio Vázquez de Mella y otros ${ }^{62}$. Ello deriva de la teoría pactista, que según Evarist Olcina tiene su primera manifestación dentro del tradicionalismo en una de las primeras cartas de María Teresa de Braganza, Princesa de Beira, al pretendiente Juan, padre del futuro Carlos VII, fechada en Baden el 15 de septiembre de 1861 y que contiene la frase: «Porque el monarca en España no tiene derecho a mandar sino según religión, ley y fuero» ${ }^{63}$. El propio Vázquez de Mella, en un discurso durante las sesiones del Congreso relacionadas con la defensa de la personalidad jurídica de la región, celebradas entre los días 30 y 31 de mayo de 1890, declarará que: «Porque aquí, la nación, mejor diré, el Estado central, ha sido la resultante de la unión de varias regiones que antes eran independientes, pero que al unirse no han podido perder aquellas prerrogati-

lista. Y estamos en 1887. Para el resto de consideraciones sobre el integrismo barcelonés remito de nuevo a mi trabajo «Introducción al estudio de la etapa barcelonesa de Sabino Arana Goiri» ya citado.

60 Ver Juan Vázquez de Mella, Regionalismo y monarquía, Madrid, Rialp, 1957, en especial su discurso pronunciado en 1918, con ocasión de la Semana Regionalista de Santiago de Compostela, donde se contiene un epígrafe titulado «El regionalismo y la religión», en pp. 133-137.

${ }^{61}$ Ver Francisco Sevilla Benito, Sociedad y regionalismo en Vazquez de Mella, Madrid, Actas, 2009, pp. 112-146.

62 Así, por ejemplo: «...estas tradiciones emanan de las diferentes leyes con que se han regido las provincias españolas, y esas leyes proceden de los diversos hábitos y costumbres engendrados por los diversos orígenes de aquellas provincias, en otros tiempos, como es sabido, reinos independientes y soberanos», en Bienvenido Comín, La política tradicional en España, Zaragoza, 1870, citado por José Luis Abellán, Historia crítica del pensamiento español, vol. 4 Liberalismo y romanticismo, Madrid, Espasa-Calpe, 1984, p. 647, nota 45. Así como Juan Vázquez de Mella en Regionalismo y monarquía, op.cit., cuando afirma que todas las regiones españolas «fueron afluentes de la nación y casi siempre Estados independientes o federados», en p. 143.

${ }^{63}$ Citado en Evarist Olcina: El carlismo y las autonomías regionales, Madrid, Seminarios y Ediciones, 1974, p. 171. 
vas y facultades esenciales a toda entidad jurídica, sobre todo si es de un orden tan superior como lo son las regiones» ${ }^{64}$.

Cuando la idea de Monarquía hispánica deja de ser el vínculo externo incontestable de la unidad política para todos los tradicionalistas, porque Carlos VII se está empezando a hacer liberal según parte de ellos, y cuando al mismo tiempo el liberalismo está empezando a anular al catolicismo como vínculo interno de España, será cuando se producirá la desafección integrista y comenzará a despuntar el nacionalismo vasco. Los integristas ya no ven al Pretendiente, por sus veleidades liberales, como la cabeza de la Monarquía que garantizará que la historia de España continúe siendo lo que había sido siempre. Este es también el suelo teórico de la ideología nacionalista. No obstante, sabemos que son necesarios otros dos factores más para desencadenar la aparición de este movimiento político y que son, sucesivamente en el tiempo: primero, la «invasión maketa», como necesidad masiva de mano de obra provocada por la súbita industrialización vizcaína, e imposible de satisfacer por la población autóctona, y que da lugar a la reacción racial-integrista de Sabino Arana ${ }^{65}$; y segundo, el desastre del 98, que provocó la escisión de la sociedad Euskalerria de Bilbao y con ella del periódico Euskalduna, ambos de la mano de don Ramón de la Sota, personaje clave para convertir al núcleo nacionalista inicial, seguidor del carisma sabiniano y de carácter casi secreto, según Javier Corcuera, en un movimiento nacionalista de masas.

Sabino Arana Goiri fue un integrista vizcaíno que construyó un mensaje político para salvar su alma y la de su pueblo vasco en un entorno hostil (léase: progresiva y mayoritariamente españolizado y, por tanto, según él, liberal). Su lema, que consideró siempre definitivo y fiel trasunto de su ideología y de su movimiento político, Jaungoikua eta Lagizarra, es suficientemente claro al respecto. Pero ello no quiere decir, ni mucho menos, que todos los integristas tuvieran esa evolución: basta cotejar la trayectoria del fundador del nacionalismo vasco con la de coetáneos y conterráneos suyos, como el ya citado Juan de Olazábal y Ramery, que nunca abandonó el integrismo político, vasco y español a la vez. Lo realmente novedoso en el mensaje político de Sabino Arana Goiri es proclamar que Bizkaya, y con ella el resto de Estados euskerianos, había sido independiente durante toda la historia hasta el siglo XIX, pero no ya respecto de

\footnotetext{
${ }^{64}$ Op.cit., pp. 189-190.

65 Asumo aquí la terminología usada por Juan José Solozábal en El primer nacionalismo vasco, Túcar, Madrid, 1975, pp.333-339, que mantiene a día de hoy toda su validez teórica.
} 
las demás regiones españolas, afirmación típica en el tradicionalismo, sino respecto de España misma. Este argumento lo utilizará profusamente desde el principio de su proselitismo, antes incluso que el lema JEL, como hemos visto, sencillamente porque es el fundamento teórico de éste.

En efecto, cuando el nacionalismo vasco llega a la fecha crucial de julio de 1936 y tiene que decidir entre Patria y Dios, su líder, José Antonio Aguirre, toma partido entonces por la Patria, en una decisión que algunos consideran la más trascendental del nacionalismo vasco en toda su historia, pero que, a la vista de los orígenes del nacionalismo vasco basados en el concepto de independencia, no fue más que su consecuencia lógica. Sabino Arana Goiri definió a su hermano como «independiente absolutista, o sea nacionalista». No le hizo falta más.

\section{Balance sobre el origen del nacionalismo vasco a la luz del concepto de independencia}

A nuestro juicio, lo más verosímil para explicar el origen del nacionalismo vasco es la simultaneidad de todo el proceso. La teoría del independentismo absoluto fue la intuición primordial que está en la base de esta ideología y que dio lugar a dos secuelas: la invención de la «revelación» de 1882 y la construcción del lema JEL. Todo se habría gestado a la vez, entre 1886 y 1887 , en plena etapa barcelonesa. El integrismo le pudo llevar a Sabino Arana de la mano en su trayectoria ideológica hasta el final, pero hizo falta algo más para desvincularse del resto del integrismo español y hacerse nacionalista vasco: «En efecto, sostenía todo nuestro credo y solo se diferenciaba de nosotros en el antiespañolismo, que significaba la separación», dice quien llegó a liderar en solitario el integrismo español a partir de 1909, el guipuzcoano Juan de Olazábal y Ramery en La Constancia de 30 de marzo de 1932 ya citada. Y ese independentismo solo se lo podía dar un factor de distinción y de separación con el resto de España que tuvo que venir necesariamente desde el concepto de raza, entendido de un modo nada católico, eso sí.

De modo que la famosa frase de «solo por Dios ha resonado» ${ }^{66}$, para definir al nacionalismo vasco, solo cabe aplicársela a los susceptibles de convertirse en nacionalistas. Esto es, la conversión es disculpable y nece-

${ }^{66}$ Recordemos que aparece en Baserritarra, 11 (11-7-1897), O.C., tomo II, p. 1333. 
saria para Sabino Arana y los conversos al nacionalismo procederán de todas las ideologías, pero, eso sí, lo que se mantiene como núcleo indiscutible es que quien se convierta al nacionalismo solo puede ser «bizkaino»o «euskeriano establecido en Bizkaya ${ }^{67}$.

El análisis con el que hemos llegado hasta aquí, sobre el origen de la ideología nacionalista, partiendo de un concepto como es el de independencia, hay que complementarlo, por tanto, con el significado que también se le da, en la ideología nacionalista originaria, al concepto de raza, usado habitualmente también en aquel momento histórico ${ }^{68}$. Entender la raza vasca como completamente separada y distinta de la española y considerarla más apta que esta para vivir en el catolicismo se convierte entonces en lo verdaderamente caracterizador del primer nacionalismo vasco. Asombra, visto desde ahora, que un mensaje así pudiera prender en su tiempo, teniendo en cuenta que estamos hablando del catolicismo, religión ecuménica, universal por principio, y de España, el país católico por antonomasia, el que más ha hecho en la historia por la difusión del catolicismo en todo el mundo.

A mediados de 1896, Félix Sardá y Salvany, a quien Sabino Arana tanto leyó y siguió para elaborar su programa político desde el integrismo ${ }^{69}$, escribió su famoso artículo «iAlto el fuego!», donde planteaba la necesidad de acabar con las banderías dentro del catolicismo, y con considerarse unos más católicos que otros ${ }^{70}$. Ignoramos si Sabino Arana

67 «A nadie, pues, rechaza el partido nacionalista, al proclamar la unión de los bizkainos: para él lo mismo es el carlismo como el integrismo como el regionalismo moderno y liberal, como el liberalismo monárquico o republicano, como cualquier otro partido liberal, españolista o hispano-liberal a la vez. Cualquiera que sea la procedencia política del bizkaino o del euskeriano establecido en Bizkaya, es admitido con júbilo, como su conversión sea sincera. Todos somos conversos.» En Baserritarra, 15 (8-8-1897), O.C., tomo II, p. 1357.

68 Ver mi trabajo «La raza en Marcelino Menéndez Pelayo», Letras de Deusto, 132, 2011, pp. 95-128.

69 De nuevo remito aquí a mi artículo «Introducción al estudio de la etapa barcelonesa de Sabino Arana Goiri » ya citado.

70 « Alto el fuego! Católicos son como nosotros muchos de nuestros hermanos carlistas; católicos son como nosotros muchos de nuestros hermanos alfonsinos; católicos son como nosotros muchos de nuestros hermanos que no gustan apellidarse con mote alguno de los arriba dichos, entre los cuales nos contamos. Bajo este concepto alargamos nuestra mano, enviamos nuestro saludo de amigos, a cuantos en los opuestos campos en que se halla dividida hoy, quizá por culpa de todos, la nación española, sostienen la misma bandera de los derechos de Dios Nuestro Señor y del reinado de su Hijo Jesucristo ( ) ¡Alto el 
llegó a leer este artículo, pero para entonces ya estaba embarcado en su flamante nave nacionalista, tras la publicación y cierre de Bizkaitarra (1893-1895) y la fundación del Bizkai Buru Batzar, embrión del PNV, el 31 de julio de 1895. El año 1896 lo dedicó a organizar el partido recién fundado, creando diferentes sociedades de propaganda y estudio ${ }^{71}$, en vísperas de sus siguientes dos actividades publicísticas de 1897: El partido carlista y los fueros basko-nabarros (febrero-marzo) y Baserritarra (mayo-agosto).

fuego entre nosotros los católicos españoles de cualquier secundaria denominación!». En Revista Popular, 11 junio 1896, pp. 370-371, citado por Antonio Moliner Prada en Félix Sardà $i$ Salvany y el integrismo en la Restauración, UAB, Servei de Publicacions, Bellaterra, 2000, p. 99 y nota 64.

71 Ver HNDV, tomo II, en especial pp. 292-320. 